\title{
UN EJEMPLO ICONOGRĀFICO DE LA IDEA DEL PODER EN TORNO AL AÑO MIL
}

\section{Victoria Cirlot}

Recientes estudios acerca de las sociedades medievales han abierto nuevos campos para la investigación y han trazado modelos que permiten el acceso a temas situados, en principio, al magen de la disciplina histórica. La clarificación teórica de los objetivos según los que debía encauzarse la historia social, ha hecho posible la aparición de nuevos estudios cuya esfera de anålisis no es ya la propia sociedad, sino la imagen que dicha sociedad se hacía de sí misma. Ello ha significado la aceptación de lo imaginario de las sociedades como un tema de investigación legítimamente histórico, en la idea de que tan real es la misma sociedad, como la imagen ideológica elaborada por determinados grupos sociales ${ }^{1}$.

El estudio de lo imaginario de las sociedades se ha basado de modo especial en las fuentes narrativas, en las fuentes procedentes de la sapientia, tal y como G. Duby las denomina ${ }^{2}$. Las interpretaciones generales de determinados textos se han apoyado en rigurosos estudios semánticos y lexicográficos, que han logrado poner de

1 Así lo ha demostrado G. DuBY, Les trois ordres ou l'imaginaire du féodalisme, Paris, Nrf, 1978, cuyo objeto de estudio fue la ehistorias de un modelo imaginario durante dos siglos.

2 Cfr. G. DUBY, op, cit., p. 184. 
relieve desde la fecha exacta de aparición de un concepto específico hasta su cambio de función significativa en un momento preciso. Así, estos estudios han logrado detectar la aparición de una nueva sociedad y los modelos imaginarios que los grupos sociales imponen ${ }^{3}$.

La apertura de la disciplina histórica al estudio de lo imaginario de las sociedades supone la aceptación de un ámbito cultural como fuente y documento. Me refiero en concreto a la obra de arte. No hay duda de que la plástica surge de lo imaginario de una sociedad y que, por tanto, de alguna forma la revela en su imagen y realidad. En ese sentido, la recepción de una obra de arte puede permitir la reconstrucción de una parcela de realidad de una sociedad. Sin embargo, si la disciplina histórica se mueve sin muchas dificultades en el anălisis del concepto, hay que señalar que no ha indicado todavía el modo de abordar la obra de arte como documento histórico. Por ello, este estudio intentará ofrecer una vía de acceso para el tratamiento de la obra de arte como fuente histórica y con ello poner de manifiesto su importancia para el análisis de lo imaginario de las sociedades. A partir de un ejemplo iconográfico concreto se intentará desvelar la concepción imaginaria que un grupo social impusiera en torno al año mil acerca del poder, de su legitimización y justificación. Si a finales del siglo X se produjo en Europa occidental una profunda ruptura con respecto a la época anterior y cuyos primeros indicios se observan en la esfera del poder político, no hay duda de que la plástica de esa misma época tendrá que revelar de algún modo aquella auténtica srevolución» que vino dererminada por el proceso de feudalización.

La Biblia de Ronda constituye - -junto con otro códice de origen también catalán, la Biblia de Ripoll- uno de los mejores manusctitos conservados del siglo XI. Fechada hacia el año mil ${ }^{4}$ ofrece abun-

3 Me refiero en especial a los estudios de J. Flori, eSémantique et société médiêvale. Le verbe adouber et son évolution au XII siècles, Annales E.S.C., 1976, pp. 915-940, por ejemplo, que ha permitido fechar con precisíón la aparición de la caballería como institución, o los del propio G. DUBY, ala difusión du titre chevaleresque sur le versant méditerranéen de la Chrétienté latines, en la Noblesse au Moyen Age, ed. por Ph. Contamine, París, P.U.F., 1976, pp. 39. 70, que permite precisar la fecha de la aparición de la sociedad feudal por la aparición en las fuentes del término miles. El cambio funcional del concepto dominus véase en G. DUBY, Les trois ordres, cit., pp. 188-189.

4 Cfr. P. KueIN, aDate et scriptorium de la Bible de Roda. Etat de recherchess, en Cabiers de Saint-Micbel de Cuxa, 3 (1972), pp. 91.101 o también 
dantes folios con miniaturas sin cromar. Todas ellas destacan por la agilidad de la línea y la calidad del dibujo; los historiadores del arte consideran que el origen formal de esta Biblia se encuentra en los salterios carolingioss. Sin embargo, si bien es cierto que el estilo artístico de la Biblia procede de la tradición carolongia, este análisis tratará de demostrar las profundas innovaciones que se pueden apreciar tanto en el ámbito iconográfico (desde la re-presentación de objetos, en especial las armas, hasta la re-presentación de grupos de personajes) como en el contenido y significado interno que resulta de la composición y del ritmo lineal. Desde esta perspectiva, la innovación es superior a la tradición, tal y como pondrá de relieve el análisis de un folio de este códice.

En el segundo registro del folio $144 \mathrm{r}^{\circ}{ }^{\circ}$ de la Biblia de Roda aparece representada una escena de guerra (Figura 1). Esta escena será el objeto del presente análisis que se construirá según tres grados, los cuales intentarán de modo sucesivo descifrar el lenguaje plástico en su totalidad. Estos tres grados de análisis son:

$1 .{ }^{\circ} \mathrm{El}$ análisis pondrá de relieve la composición del folio, es decir, las líneas imaginarias o reales que el artista trazó para la situación y localización de los objetos representados.

2. ${ }^{\circ}$ Se llevará a cabo un detenido estudio de la re-presentación. Este es el ámbito propio donde se sitúa el análisis iconográfico, pues su fin más inmediato consiste en el reconocimiento de los objetos re-presentados.

3. ${ }^{\circ}$ Igualmente será necesario el análisis de la imagen. Con este concepto se aludirá a los elementos plásticos puros que se encuentran en toda obra de arte. El lenguaje plástico se sitúa siempre en esa doble manifestación de re-presentación/imagen y su comprensión global sólo resulta posible en un análisis que logre distinguir ambos fenómenos ${ }^{6}$.

F. VATtIONI, La vetus latina di Tobia enlla Biblia di Rodas, Revista de Teología, 3 , Pp. 173-200

s Cfr. W. Neuss, Die katalanische Bibelillustrationen und die altspaniscbe Buchmalerei, Bonn-Leipzig, 1922.

6 La distinción entre imagen y re-presentación se debe a la fenomenología y aplicada al campo del arte a H.G. GADAMER, Vérité et métbode. Les grandes lignes d'une hermenéutique pbilosophique, París, Ed. du Seuil, 1976, pp. 27-99; el autor utiliza los conceptos de Bild (imagen) y Abbild (re-presentación). Al mismo tiempo, profesores de la Bauhaus realizaron ya etraduccioness de representaciones en imágenes, cfr. J. IITTEN, Art de la couleur, París, Dessain et 


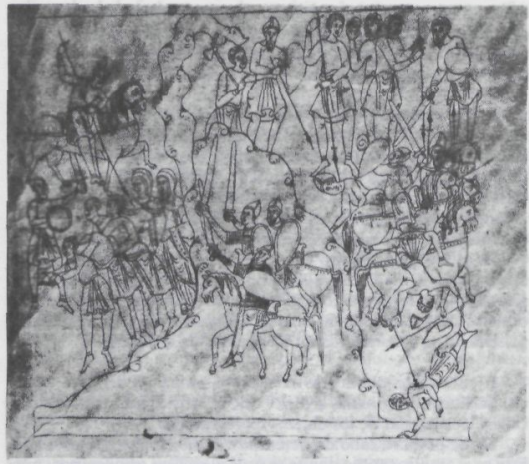

Figura 1.- Biblia de Roda folio 144 r. registro inferior (Bibl. Nat. de Paris, ms. lat. 6).

Estos tres grados de análisis tratan de abordar la obra de arte en su totalidad plástica: desde su estructura interna (composición) hasta los elementos puros inherentes al ámbito de pintura o miniatura (imagen), pasando por el estudio de la articulación de unos objetos, personajes y escena (re-presentación). Sin embargo, cada uno de estos grados de análisis (composición, re-presentación e imagen) poseen una esfera de propiedad cuya adecuación y conjunción nos ofrece un resultado final, objeto de nuestra percepción. Cada uno de estos tres grados reflejará aspectos distintos de lo real y de lo ima-

Tolra, 1978, pp. 76, 147 y 148. Este método de análisis plástico ya lo utilicé, sìguiendo las directrices establecidas para ello en un curso de la Universidad Autonoma de Barcelona: Ideología y representación en la Edad Media impartido por el profesor J.E. Ruzz DOMÉNEC en el curso 1976/77, en: V. CIRIOT, «Ornamento y abstracción: ritmos lineales en la pintura de Sant Martí Sescorts, Estudios ProArte, 9 (enero-marzo 1977), pp. 70-83. 
ginario de la sociedad que hizo posible esta obra de arte y su conjunción nos ofrecerá una imagen concreta respecto a un tema preciso: la idea del poder detentada por ciertos grupos sociales elevados en torno al año mil.

\section{1.et grado de análisis: la composición}

Toda esta plástica se ordena según un principio de construcción. El artista transforma los elementos de la realidad y las relaciones que en ella mantienen, para crear la unidad y el sentimiento de totalidad. De ahí que sea precisamente en la construcción donde mejor se puede apreciar la voluntad subjetiva del artista y, por consiguiente, su ideología. La atención plástica en la estructura de relaciones culminó con el constructivismo del siglo XX; sin embargo, en toda obra de arte resulta posible apreciar esa red de relaciones que se ha basado en principios distintos según las diversas circunstancias históricas. Los artistas renacentistas racionalizaron el principio constructivo y lo denominaron genéricamente composición, concepto que aquí utilizaremos también para referirnos a la construcción interna de la plástica en el arte románico?.

En el folio $144 \mathrm{r}^{\circ}$ de la Biblia de Roda, la composición del plano se sustenta en una figura geométrica triangular. Dicho triángulo se encuentra sugerido por una línea ascendente-descendente ondulada y en posición oblicua. Así, el espacio se descompone en dos zonas fundamentales (Figura 2): aquella delimitada por el propic triángulo (A) y aquella otra situada fuera de la figura geométrica (B). Esta segunda zona se abre a derecha e izquierda del triángulo y en ambos lados se subdivide a su vez en dos partes distintas $\left(B_{1}\right.$ y $B_{2}$ ). En efecto, si observamos la situación de los personajes representados, se pondrá de relieve la voluntad del artista de crear en ambos lados una parte superior (B) y otra inferior $\left(\mathrm{B}_{1}\right.$ y $\left.\mathrm{B}_{2}\right)$. Así, la composición de este folio resulta simétrica, siendo su centro y eje la figura geométrica triangular.

\section{2. ${ }^{\circ}$ grado de anâlisis: la re-presentaciôn}

El análisis de la re-presentaciôn seguirá el orden establecido por la composición interna del folio.

7 Para el estudio de la composición, véase J. ITten, op. cit., pp. 144-149; también cfr. T.W. ADORNO, Aesthetische Theorie, Frankfurt am Main, Suhrkamp, 1977, t. 2, p. 91. 


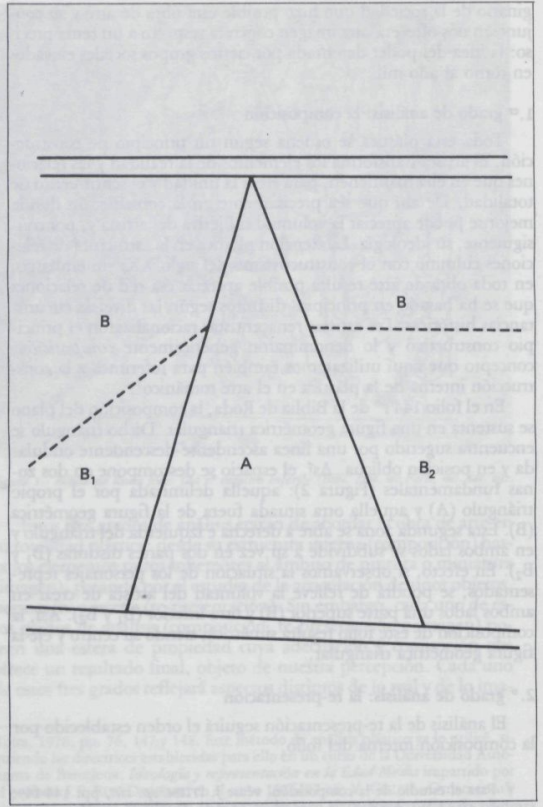

Figura 2.- Composición. 
En la zona $\mathrm{A}$ aparecen tres guerreros a caballo perfectamente equipados: visten lorigas de mallas clavadas y se protegen con escudos en forma de almendra y cascos cónicos. Presentan un tipo de armamento defensivo que carece de precedentes en la iconografia anterior y que, en cambio, perdurará en la plástica del siglo XI.

En los salterios carolingios no aparece nunca un modo de representación de cota de mallas similar al que encontramos en este ejemplo de la Biblia de Roda: las lorigas dibujadas en el Salterium Aureum o en el Manuscrito de Leiden ofrecen en su interior unos círculos minúsculos que aluden a los *anillos entrelazados». Por el contrario, en este folio de la Biblia de Roda aparece un dibujo cuadriculado, que se refiere a un nuevo modo de fabricación de lorigas, aquellas realizadas a base de mallas cuadriláteras clavadas y cuya primera documentación se encuentra precisamente en las Biblias de Roda o de Ripoll. Asimismo, en esta re-presentaciôn de cota de mallas se observa otra caracteristica: el rectángulo dibujado en la parte superior que alude a una pieza que se alzaba para la protección de cuello y mentón. Este es el tipo característico de cota de mallas del siglo XI, tal y como también documenta el famoso tapiz de Bayeux. También, la forma de almendra que presentan los escudos, constituye un tipo nuevo en esta arma defensiva. Se trata del tipo de escudo, mal denominado normando, que a lo largo del siglo XI aumentó considerablemente sus dimensiones. Los tres guerreros sostienen en alto sus espadas cuyas formas también resultan nuevas con respecto a las anteriores, pues han sustituido los pomos *en forma de nuez* característicos de los siglos VIII al X, por los pomos discoidales ${ }^{8}$. Así, el artista de la Biblia de Roda nos presenta a unos guerreros cuya fisonomía resulta distinta, debido al tipo de armamento utilizado.

Si bien la espada constituye un arma ofensiva fundamental, no hay duda de que al mismo tiempo poseía un significado superior al meramente funcional. Desde un punto de vista iconográfico, la trascendencia de un objeto del ámbito de su estricta materialidad al ámbito del significado superior viene determinada por varios elementos. Aquí destacaremos tres factores que nos parecen fundamentales: 1. la relevancia que en la composición interna se otorga al

8 Para una mayor información del armamento de la Biblia de Roda y de la demostración de su carácter innovador con respecto a la iconografía precedente, véase V. CIRLOT. El armamento catalän de los siglos XI al XIV, tesis doctoral leída en 1980 en la Universidad Autónoma de Barcelona (en prensa). 
objeto, 2. la posición en que se encuentra el objeto y 3. una clara sustracción del objeto a su esfera de funcionalidad práctica. La representación de las espadas sostenidas por los tres guerteros cumple estas premisas: en primer lugar, la representaciōn de estas espadas se sitúa en el centro de la composición, dentro del triangulo y, por tanto, en el espacio más destacado del folio; en segundo lugar, las espadas aparecen en una posición específica, sostenidas en alto por los guerreros y, en tercer lugar, no se encuentran en un contexto que ponga de relieve su función como arma ofensiva. En contraposición a las otras dos espadas representadas en el resto del folio (B), en la zona $A$ aparecen aisladas y ajenas al movimiento que permite el manejo del arma con función de tajo. Todo ello induce a creer que en esta re-presentación de la zona A, la espada constituye un simbolo.

La simbología tradicional ha entendido este objeto como un símbolo de conjunción, en especial, durante la Edad Media en que asumió la forma de cruz ${ }^{9}$. El significado equívoco y multiple del símbolo puede reducirse con su circunscripción histórica y según su contexto iconográfico. Dentro de una acepción general del significado de este objeto en las sociedades medievales, la espada se entiende como símbolo de poder y soberanía. Son muchos los ejemplos iconográficos que permiten tal atribución simbólica a la espada. Recordemos tan sólo aquellas representaciones de los salterios carolingios que nos presentan al emperador sedente en el trono sosteniendo la espada, o aquellas otras en los sellos catalanes donde los condes aparecen también empuñando la espada en alto, o bien yacente sobre las rodillas ${ }^{10}$.

En este folio de la Biblia de Roda, la espada aparece representada en el centro de la composición y es sostenida en alto por los guerreros a caballo. Su situación ejecial y posición vertical permiten asimilar la espada a otro símbolo, el árbol, adoptando así el significago fundamental del árbol que consiste en simbolizar la vida.

Así, la espada, símbolo de poder y de vida, se encuentra en manos de tres guerreros, sin duda los nuevos detentadores del poder al

9 Cfr. J.E. CirLot, Diccionario de símbolos, Barcelona, Labor, 1969, pp. 202-204.

10 Abundante documentación de los salterios carolingios en A. MERTON, Die Bucbmalerei in St. Gallen von neunten zum elften Jahrbundert, Leipzig, K.W. Hierseman, 1912; ver los sellos de Alfonso II y Jaime I en F. SAGARRA. Sigillografía catalana. Inventari, descripció $i$ estudi dels segells de Catalunya, Barcelona, 1916. 
filo del año mil, aquellos que a finales del siglo $\mathbf{X}$ llevaron a cabo una auténtica usurpación del poder a travếs de la actividad guerrera y que los documentos denominan con el concepto domini. La interpretación de estos tres personajes de la zona A como domini se justifica fundamentalmente por su ostentación de la espada como emblema, pero también porque contrastan con el resto de los personajes re-presentados por el completo y perfeccionado armamento con el que se protegen. Finalmente, el artista ha tenido la intención de destacarlos, al situarlos en el triángulo, auténtico eje de la composición.

Estos domini se manifiestan en la iconografia de principios del siglo XI como los mejor equipados y, de modo fundamental, como los portadores de espadas. Detentadores de las potestas, habrian de conceder una nueva dimensión significativa a la espada, porque esta arma revelaria la nueva función ejercida por los guerreros en la sociedad del siglo XI. En esta miniatura, la espada en alto alude también a la idea de protección y seguridad, al nuevo orden impuesto por los señores feudales, basado en la actividad guerrera como la única legitimización y justificación del modo de producción señoriall ${ }^{11}$.

Si el origen de la composición del folio se encuentra en el trazado de una figura geométrica en la parte central, el análisis de la representación nos pone de manifiesto que la escena desencadenada en el espacio de este folio es el resultado de la aparición de tres guerreros a caballo, tres domini con el símbolo de poder y de seguridad: la espada.

En la parte superior de la zona B encontramos, a la izquierda del plano, a dos guerreros: uno a caballo protegido con casco y manejando la lanza como arma punzante, y otro guerrero a pie con un escudo redondo y una espada. Ambos guerreros visten una simple túnica. La dificultad y la técnica que exigía el manejo de la lanza como arma punzante, permite poner en duda la interpretación de

11 Entre los significados que se le han otorgado a la espada durante la Edad Media destacaré tres: la espada como signo de poder, ofr. P.E. SCHRAMM, Herrsschaftszeichen und Staatssymbolik, Suttgart 1945-46; la espada como emblema, cfr. G. DUBY, Art roman, art gotbique. L'Europe as Moyen Age, París, Arts et Mćticrs graphiques, 1979 , p. 28 y del mismo autor, Le Temps de cathédrales, París, Nrf, 1976, p. 22; la espada como símbolo de seguridad y obra de arte, $c$ fr. J.E. RUIz DOMENEC. El origen de la obra de arte feudal, Bellaterra, Universidad Autónoma, 1979, p. 69. 
estos personajes como simples campesinos ${ }^{12}$. Se trata de auténticos profesionales de la guerra, hombres habituados a combatir y cuya vida ha transcurrido en el constante ejercicio de las armas. El hecho de que no aparezcan equipados con cotas de mallas no constituye un dato relevante para su descalificación como guerreros profesionales. Ello tan sólo pondría de relieve las condiciones materiales de la guerra durante las primeras décadas del siglo XI que, al parecer, no permitieron el completo equípamiento de los guerreros por el elevadísimo coste de la pieza fundamental del armamento defensivo ${ }^{13}$. Así pues, resultaría más adecuado reconocer en estos personajes a aquel grupo social que en la documentación escrita de finales del siglo $\mathrm{X}$ aparece denominada con el concepto de milites. De igual modo deberán interpretarse los guerreros representados a la derecha del plano donde tiene lugar una auténtica lucha distribuida según las partes $\mathrm{B}$ y $\mathrm{B}_{2}$.

El reconocimiento de estos personajes como milites ha venido determinado porque todos ellos manejan armas ofensivas: lanzas, espadas, hachas. De ello se puede concluir que la iconografía de miles durante las primeras décadas del siglo XI no nos ofrece aún la imagen de un guerrero completamente armado, cual por ejemplo aparece en Bayeux, ni tampoco necesariamente la de un guerrero a caballo. Según la re-presentación de este folio, el requisito funda-

12 Para el mancio de la lanza con función de punzamiento, véase V. CirLor. El armamento catalán, cit., pp, 69-87. El análisis de esta función de la lanza demostró la técnica que se exigia para manejar el arma de este modo. Por ello no estoy de acuerdo con la interpretación de P. BONNASsIE, La Catalogne du milieu du $X^{\prime}$ à la fin du X' siècle, Toulouse, Association des Publications de l'Université de Toulouse-le Mirail, 1975, de este folio. El autor considera que se trata de campesinos armados (p. 306, t. 1). Este análisis intentará demostrar que el folio acoge iconográficamente la aparición de los profesionales de la guerra, de los milit. tes.

13 Para el elevadísimo coste de la loriga, véase F. BUTtın, Du costume militaire asu Moyen Áge et pendant la Renaissance, Barcelona, Memorias de la Real Academia de Buenas Letras, 1971, donde después de analizar documentos del siglo IX,

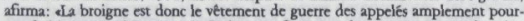
vus de biens matérielss. (p. 14). La iconografia parece demostrar que esta situación perduró en el primer cuarto del siglo XI. Posiblemente una de las mayores revoluciones operadas en el armamento de la primera edad feudal no consistió tanto en la uransformación tipológica de las armas o en cambios funcionales, sino en su difusión. Así, por ejemplo, en el tapiz de Bayeux vemos bajo el título HIC EST MILES $a$ un guerreto a pie pero completamente equipado. Sin duda, esa fue la aspiración de los señores durante el siglo XI: lograr equipar a sus guerreros con lorigas y yelmos. 
mental del miles consiste en tener y saber manejar un arma ofensi$\mathrm{va}$, pero tanto puede ser un miles-cabalarius como un miles-pedes. Ello se explica por razones tácticas en la forma de guerra de esta época. Durante la primera mitad del siglo XI el caballo no fue utilizado como instrumento de guerra, pues no constituía un elemento indispensable para el manejo de ningún arma según un modo específico. La utilización del caballo como elemento de guerra se encuentra estrechamente relacionada con la función de choque de la lanza: en efecto, cuando la lanza aumentó su peso y grosor y se introdujo bajo el brazo, el guerrero necesitaba el impulso, la fuerza y la velocidad del caballo para cargar contra el adversario. Pero a principios del siglo XI, la lanza no poseía todavía función de choque, sino que se manejaba como un arma punzante. El guerrero podía conceder tal función a la lanza tanto a caballo como a pie ${ }^{14}$. Por ello, no creo que el miles tuviera que ser necesariamente un guerrero a caballo, puesto que el animal no le servía para conceder a ninguna de sus armas una función determinada.

Así, el miles aparece en la iconografía como un guerrero con técnica de utilización de armas ofensivas, pero la identificación de los personajes de la zona B como miles se basa también en otro factor que no se revela en el ámbito iconográfico sino más bien en el de la composición.

Si en la documentación escrita el par de conceptos dominusmiles aparecen constantemente relacionados, también en el lenguaje plástico se puede advertir dicha relación de dependencia. La estructura binaria de esta organización social aparece plasmada en la propia composición del plano, según la cual éste se didivía en dos espacios: el A, lugar donde se inscriben los domini y el B, zona donde aparecen los milites. La aparición del triángulo en la zona central supone la descomposición del plano en dos espacios indesligables, siendo además la zona interna del triángulo, eje de simetría, la que desencadena el espacio B. De este modo, la dependencia entre dominus-miles en la cual se basaron las nuevas relaciones de la sociedad feudal, se manifiesta plásticamente en la concepción binaria del espacio.

La zona B situada a ambos lados del triángulo se subdividia a su

14 Véase la demostración de cllo en V. Ciruor, El armamento catalán, cit., pP. 69-87. Un completo análisis de la lanza con función de choque y del caballo como instrumento de guerra, véase en F. BuTTIN, «La lance et l'arrêt de cuirasse», Archaellogia, XCIX (1965). 
vez en dos partes simétricas que se sugerian por la disposición de los personajes.

En efecto, la zona B de la derecha del plano representa una escena de lucha en la cual se distinguen ambas partes del enfrentamiento. En la parte superior se encuentran los guerreros vencedores y en la parte inferior $\left(B_{2}\right)$ los guerreros vencidos, muertos o dispuestos para la huida. A la parte inferior $\mathrm{B}_{2}$ se contrapone, según la composición del plano, la parte inferior $\mathbf{B}_{1}$. Estos personajes se distinguen de todos los demás por la carencia de armas. Ese es su rasgo más sobresaliente junto con la actitud de clemencia y sumisión que parecen adoptar. En este caso el valor del gesto, las manos extendidas, supera a cualquier objeto de reconocimiento iconográfico. Tales personajes aluden por la carencia de armas y por su gesto a aquel grupo social denominado con la expresión multitudo inermis vulgi o también con el concepto de pauperes.

El concepto pauper aparece ya en la documentación carolingia y perdura en las fuentes de los siglos XIII y XIV. Sin embargo, durante estos tres o cuatro siglos, el concepto poseyó distintos significados que en principio nada tenían que ver con la pobreza o indigencia. En un rápido bosquejo de la evolución del significado social de este término, cabria señalar que en la época carolingia los pauperes aparecen estrechamente ligados al emperador y su función estricta consistía en su servicio en el ejército: son los pauperes qui in exercitum ire debent. Por el contrario, a principios del siglo XI, el concepto pauper alude al inermis, al necesitado de protección por parte de los que poseen armas. Sólo la aparición de las ciudades y la expansión de la economía monetaria, a partir de las primeras décadas del siglo XII, supondrá la significación de la paupertas como pobreza en el sentido económico del término. En este sentido, resulta ilicito identificar a los personajes de la zona $B_{1}$ como pauperes, aunque los estudios iconográficos sobre este grupo social hayan determinado como datos relevantes el hecho de que aparezcan como pobres: descalzos, sin ropa, pidiendo limosna ${ }^{15}$. En este folio

15 Para la cuestión de la paspertas y la evolución semántica del término pauper, véase K. Bost., «Potens und Pauper. Begriffsgeschichtliche Studien zur gesellschaftlichen Differenzierung im frühen Mittelalter und zum "Pauperismus" des Hochmittelalterss en Fräh formen der Gesellschaft im mittelalterlicben Europa, München-Wien, R. Oldenbourg Verlag, 1964, pp. 106-135. Una demostración de que el concepto pauper nada turo que ver con la indigencia en la época carolingia, en J.E. RUIz DOMENEC, \&Un "Pauper" rico en la Cataluña carolingia a fines del siglo VIIIs, Boletín de la Real Academia de Buenas Letras de Barcelona, XXXVI 
de la Biblia de Roda, estos personajes no aparecen como epobres» sino tan sólo como desprovistos de armas y en oposición al grupo social formado por los milites.

En suma, según pone de manifiesto este análisis, existe una perfecta adecuación del contenido entre la composición y la representación del folio cuya iconografía nos ofrece una concepción nueva de la sociedad. La situación de los portadores de espadas fuera del espacio en que se va a desarrollar la lucha y su ubicación en el centro de la composición tiene como fin su distinción del resto de los guerreros. Al mismo tiempo, la apertura de dos espacios en la composición busca la expresión de una relación binaria, aquella entre los portadores de espadas y los demás guerreros, en definitiva, la relación entre el dominus-miles, indicio inequívoco de la aparición de la sociedad feudal. Además, tanto la composición como la representación inciden en la advertencia de que el espacio B, los milites, sólo podrá existir en virtud del espacio A, los domini y su símbolo, la espada. En el espacio $\mathrm{B} / \mathrm{B}_{2}$ se escenifica la actividad propia de esa nueva sociedad: la guerra. El poder que simboliza la espada se ha adquirido mediante la creación del vínculo de dependencia entre dominus-miles y mediante la actividad guerrera. Ante ese nuevo poder sólo caben dos soluciones que el espacio A ordena y separa simétricamente en $B_{1}$ y $B_{2}$ : la muerte, cual nos indica la terrible re-presentación del guerrero caído del caballo y atravesado por una lanza, o bien la sumisión al nuevo orden simbolizado en la espada, cual demuestra el gesto del grupo de personajes interpretado como pauperes.

Según esta interpretación de la iconografia de este folio, la sociedad aparece representada desde la perspectiva de un modelo imaginario que acepta el nuevo orden social y la nueva idea de poder. La militia no apatece entendida aquí como malitia sino que se la presenta ejerciendo su poder con justicia. La resistencia con armas a su poder significa la muerte $\left(B_{2}\right)$, pero la sumisión merece cle-

(1975-1976), pp, 5-14. El significado de paxper en el siglo XI como desprovisto de armas, véase en G. DUBY, eLes laïes et la paix de Dieus, en I Laici nella esocietas christianas dei secoli XI e XII, Atti della terza Settimana internazionale di studio Mendola, 21-27 agosto, 1965, Milano, Societá editrice vitza e pensiero, 1968, p. 453 en especial. En cualquier caso, los estudios iconográficos sobre los pasupenes de los siglos XI y XII han querido ver en la pobreza los indicios de reconocimiento de este grupo social, cfr. Y. LABANDE-MAILFERT, ePauvreté et Paix dans l'iconographie romane (XI'-XIle siècle), $*$ en Etudes sur l'bistoire de la pauvreté, sous la direction de Michel Mollat, París, Publications de la Socbonne, 1974, pp. 319-347. 
mencia $\left(B_{1}\right)$. En efecto, en los primeros concilios de paz no se prohibió el derecho a combatir. Los nuevos señores podían ejercer el dominio en su distrito, luchando contra aquellos que ofrecían oposición. Los concilios sólo condenaban el pillaje, el combate contra los pauperes, pero éstos debían someterse al señor del territorio, al dominus toci y a sus guerreros, los milites ${ }^{16}$. Esta es la ideología de la paz de Dios, que intentó una legitimización del nuevo orden social, determinado por el proceso de feudalización. Desde esa misma ideología parece presentarnos esa sociedad el folio 144 de la Biblia de Roda: los domini pueden ejercer con justicia su poder en su territorio a través de los milites. No existe condenación para las guerras privadas si el enfrentamiento es con guerreros armados; la paz se debe establecer con los que carecen de armas, los pauperes.

La composición y la re-presentación no agotan el lenguaje plástico de una obra de arte. Por el contrario, la plástica opera con los elementos que le son propios en estado puro y que aparecen ocultos en la re-presentación. Despojar a la iconografía de su representación significa ir en búsqueda de la imagen, que se intuye como el significado último de la obra de arte sin cuyo desciframiento la lectura resultaría incompleta.

\section{3. er grado de análisis: la imagen}

La relevación de la imagen se obriene mediante la traducción de la re-presentación a los elementos plásticos puros: el punto y la línea ${ }^{17}$. Ello significa suponer que el principio plástico desencadenante de la obra de arte es abstracto. No es mi intención establecer aquí un principio teórico sobre la obra de arte en general, pero no hay duda de que existen sistemas de re-presentación que se basan en un principio elemental abstracto, tal y como puede apreciarse en el denominado earte románicos. La percepción de cualquier obra de arte del siglo XI nos sitúa ante la evidencia de que las líneas, los puntos y los colores poseen un valor que a veces se escapa de la re-

16 Cfr. G. DuBy, Les laḯs, cit., p. 45s. Para un estado de la cuestión del problema de la paz de Dios en Cataluña, véase J.E. RuIz DOMENEC, ^Guerra y agresión en la Europa feudal. El ejemplo cataláns. Quaderni Catanesi di Studi classicie medievale II, núm. $=(1980)$, pp. 265-324.

17 Asi lo entendió W. KANDINSKY, Poins-ligne-plan, en Écrits complets (La

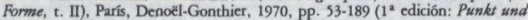
Linie zu Flache, 1926). 


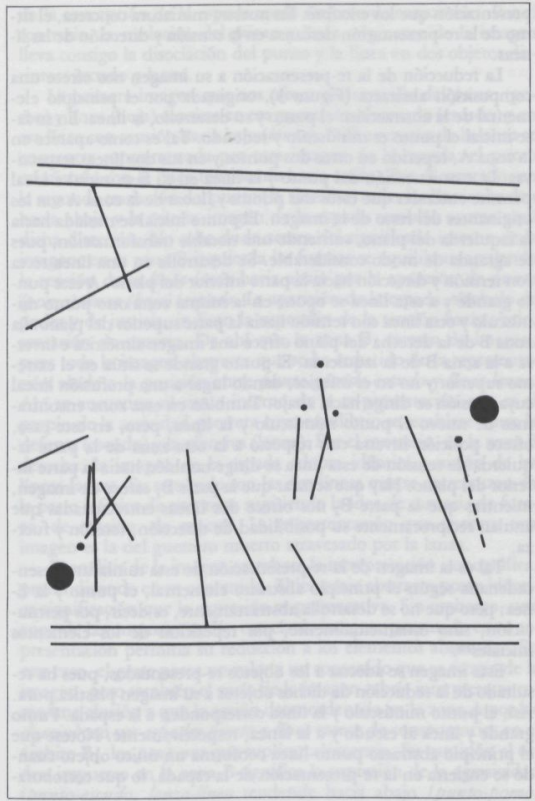

Figura 3.- Imagen. 
presentación que los encubre. En nuestra miniatura concreta, el ritmo de la re-presentación descansa en la tensión y dirección de las líneas.

La reducción de la re-presentación a su imagen nos ofrece una composición abstracta (Figura 3), originada por el principio elemental de la abstracción: el punto y su desarrollo, la línea. En su fase inicial el punto es minúsculo y redondo. Tal es como aparece en la zona A, repetido en otros dos puntos y en sus dos líneas respectivas. La manifestación del punto y la línea en su fase inicial e ideal permite entender que estos tres puntos y líneas de la zona A son los originantes del resto de la imagen. El punto inicial se traslada hacia la izquierda del plano, sufriendo una notable transformación, pues se agranda de modo considerable. Se desarrolla en una línea recta con tensión y dirección hacia la parte inferior del plano. A este punto grande y a esta línea se opone en la misma zona otro punto minúsculo y otra línea con tensión hacia la parte superior del plano. La zona $\mathrm{B}$ de la derecha del plano ofrece una imagen simétrica e inversa a la zona B de la izquierda. El punto grande se sitúa en el extremo superior y no en el inferior, dando lugar a una profusión lineal cuya tensión se dirige hacia abajo. También en esta zona encontramos de nuevo el punto minúsculo y la línea, pero, en este caso, ofrece posición inversa con respecto a la otra zona de la parte izquierda: la tensión de esta línea se dirige también hacia la parte inferior del plano. Hay que señalar que la parte $B_{1}$ carece de imagen, mientras que la parte $\mathrm{B}_{2}$ nos ofrece dos líneas entrecruzadas que anulan recíprocamente su posibilidad de dirección, tensión y fuerza.

Tal es la imagen de la re-presentación de esta miniatura desencadenada según el principio abstracto elemental, el punto y la línea; pero que no se desarrolla abstractamente, es decir, por permutación, sino ornamentalmente, por repetición de los elementos iniciales ${ }^{18}$.

Esta imagen se adecua a los objetos re-presentados, pues ha tesultado de la reducción de dichos objetos a su imagen plástica pura. Así, el punto minúsculo y la línea corresponden a la espada. Punto grande y línea al escudo y a la lanza, respectivamente. Nótese que el principio abstracto punto-línea conforma un único objeto cuando se encierra en la re-presentación de la espada, lo que corrobora-

18 Así lo pude comprobar en V. CIRLot, Omamenzo y abstracción, cit. 
ria la concepción de la espada como símbolo de conjunción. Por el contrario, la traslación del punto y línea originante de la imagen lleva consigo la disociación del punto y la línea en dos objetos distintos: escudo y lanza.

La primera imagen que nos ofrece el desarrollo del punto (pomo) y línea (hoja) consiste en ese punto transformado (escudo) y en esa línea con tensión hacia bajo (Lanza). Dicha tensión de la lanza se encuentra contrarrestada por otra imagen de la espada: el punto minúsculo con la línea tensionada hacia arriba. Por el contrario, en la segunda traslación del punto (B, derecha) todas las líneas tienden hacia abajo y la tercera imagen de la espada también asume aquí dicha dirección. No cabe duda acerca del significado interno de la imagen: en la zona B izquierda las fuerzas se equilibran anulando la tensión de la linea-lanza hacia abajo por la aparición de punto (pomo)-linea (boja)/espada. La aparición de la espada, símbolo de poder y de justicia, indican la supresión de la tensión hacia abajo, sensación de muerte. De ahí que la zona $\mathrm{B}_{1}$ carezca de imagen, pues toda la imagen abstracta que se ha reducido de la representación alude a la posición entre punto-grande-escudo y linea-lanza. Ahí se encuentra el ritmo interno de la re-presentación que es el propio de la actividad guerrera cuyo equilibrio se establece entre la defensa (escudo) y la ofensiva (lanza). Por el contrario, en la zona B derecha, la imagen de la espada adopta idéntica posición de las líneas-lanzas. Su resultado son las dos líneas que se entrecruzan en la parte inferior de esta zona sugiriendo la idea de carencia de fuer$z a$, de tensión, de muerte. La re-presentación que encierra esta imagen es la del guertero muerto atravesado por la lanza.

El análisis de la imagen corrobora la interpretación iconográfica, profundizando en su contenido. El lenguaje abstracto posee idéntica significación que la expresión re-presentativa. Sin embargo, una zona de la composición, $\mathrm{B}_{1}$, carecía de imagen, pues nada en su representación permitía su reducción a los elementos abstractos. En este caso, el gesto posee un valor y un contenido que se escapa de la imagen, pero también el vacío de la imagen cabría interpretarse como una alusión a que la acción desencadenada en la zona A por los domini con sus espadas-punto y linea carece de consecuencias en el ámbito $\mathrm{B}_{1}$, los pauperes que suplican clemencia. Su sumisión al orden impuesto en la zona B significa la supresión de la agresividad (punto-escudo, lanza-linea tendende hacia abajo Ipunto-pomo, linea-hoja tendente hacia arriba) que por el contrario se desarrollará en la zona B derecha. 
Si bien la imagen de esta miniatura se adecua totalmente a la re-presentación pues los elementos plásticos extraídos corresponden a determinados objetos re-presentados, existe, sin embargo, una línea que no corresponde a ningún objeto re-presentado y que tampoco es abstracta, sino estrictamente ornamental. Se trata de la línea ascendente ondulada que en su reducción formal daba lugar a la figura triangular considerada como el eje composicional del folio. Esta linea, cuya imagen abstracta es un triángulo, reproduce un esquema muy característico en la ornamentación: la linea ondulada con crestas.

El simbolismo ornamental ha atribuido un significado a los cuatro tipos fundamentales de ornamentación, asimilándolos a los cuatro elementos de aire, fuego, tierra y agua. Así, la línea ondulada alude al aire por su carácter etéreo, la línea quebrada en ángulo recto a la tierra por la sensación de firmeza y solidez que produce, la línea quebrada en ángulo agudo al fuego. Finalmente, la línea ondulada con crestas simbolizaría el agua, por reproducir el movimiento de las olas ${ }^{19}$.

Si establecemos la relación entre imagen y re-presentación para la línea de nuestro folio, observaremos que a la imagen abstracta que de ella resulta, el triángulo, se sobrepone su re-presentación ornamental, la línea ondulada con crestas (Figura 4), símbolo de agua y disolución. El significado de esta línea se deberá deducir de la conjunción imagen-representación que, en este caso, no se adecuan sino que se oponen. Así, la linea ornamental simboliza la disolución de la figura geométrica, el triángulo, que debe advertirse como imagen de lo ternario y cuyo significado superior consiste en ser emblema de la Trinidad o de las grandes tríadas ${ }^{20}$. La imagen ternaria conforma asimismo una estructura latente de ordenación social que buscaba la reproducción del universo celestial en el mundo terrestre y que se encontraba estrechamente ligada a la idea imperial. Así surgió al menos la teoría trifuncional en el Occidente europeo hacia el año mil.

En efecto, la concepción del poder en torno al año mil se basaba en una idea ternaria de la sociedad, según la cual el poder ostentado por el emperador procedía de una delegación divina. La sociedad se encontraba dividida en tres órdenes con sus tres funciones

19 Cfr. L. Cirlot, «Simbolismo del ornamentos, en Historia del Mundo insólito. Magia-Ritos-Simbolos, Barcelona, ed. Marin, 1973, pp. 216-225.

20 Cfr. J.E. CRLot, Diccionario de símbolos, cit., p. 460. 


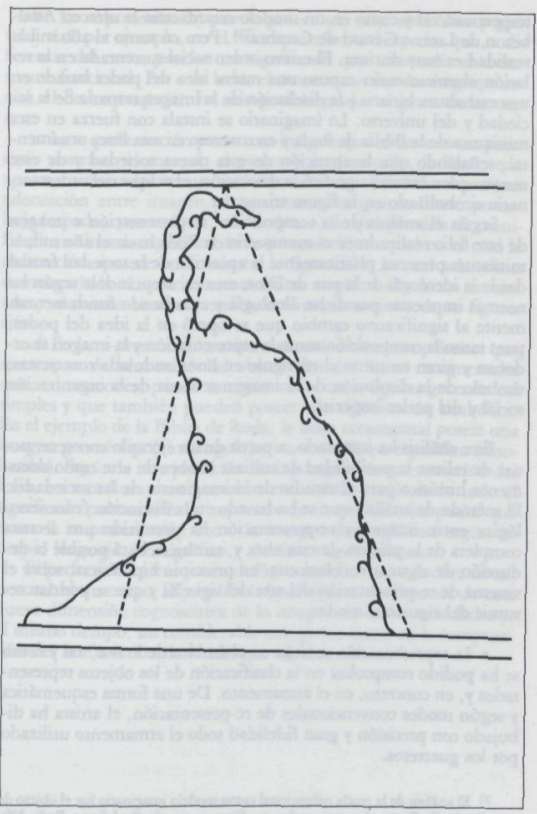

Figura 4. Represensación anownental e imagen triangular. 
respectivas, tal y como en un modelo retardatario la ofrecen Adalberon de Laon o Gérard de Cambrai ${ }^{21}$. Pero en torno al año mil la realidad es muy distinta. El nuevo orden social sustentado en la relación dominus-miles supuso una nueva idea del poder basado en una estructura binaria y la disolución de la imagen ternaria de la sociedad y del universo. Lo imaginario se instala con fuerza en esta miniatura de la Biblia de Roda y en concreto en esta línea ornamental, señalando que la aparición de esta nueva sociedad y de este nuevo orden binario significó la disolución, el eclipse del orden ternario simbolizado en la figura triangular.

Según el análisis de la composición, re-presentación e imagen de este folio realizado en el monasterio de Roda hacia el año mil, la miniatura presenta plásticamente la aparición de la sociedad feudal desde la ideología de la paz de Dios, esto es, aceptándola según las normas impuestas por dicha ideología y atendiendo fundamentalmente al significativo cambio que se operó en la idea del poder, pues tanto la composición como la representación y la imagen se ordenan y giran en torno al triángulo en línea ondulada con crestas, símbolo de la disolución de la imagen ternaria de la organización social y del poder imperial.

Este análisis ha intentado, a partir de un ejemplo concreto, poner de relieve la posibilidad de utilizar la obra de arte como documento histórico para el estudio de lo imaginario de las sociedades. El método de análisis que se ha basado en la distinción fenomenológica entre imagen y re-presentación ha permitido una lectura completa de la plástica de esta obra y, también, hará posible la deducción de algunas conclusiones, en principio hipotéticas, sobre el sistema de re-presentación del arte del siglo XI y que se podrían resumir del siguiente modo:

a. La representación se sitúa en el ámbito de lo real, tal y como se ha podido comprobar en la clasificación de los objetos representados y, en concreto, en el armamento. De una forma esquemática y según modos convencionales de re-presentación, el artista ha dibujado con precisión y gran fidelidad todo el armamento utilizado por los guerreros.

21 El análisis de la teoría trifuncional como modelo imaginario fue el objeto de estudio de G. DUBY, Les trois ordres ou l'imaginaire du féodalisme, Paris, Nfr, 1979, pp. 25-76. 
b. La re-presentación puede poseer un valor simbólico y gestual. Así, por ejemplo, en el folio aparecían tres espadas que, a diferencia del resto, poseían un significado que trascendía al meramente funcional. Por otro lado, el reconocimiento de un grupo social, el de los pauperes, ha sido posible gracias al gesto de las manos.

c. La re-presentación posee una imagen que se basa en un principio abstracto elemental, el punto y su desarrollo, la línea, que aparecen reiterados en un ritmo ornamental. Existía una perfecta adecuación entre imagen y re-presentación (punto-línea: pomohoja (espada), punto-línea: escudo lanza), lo que pondría de manifiesto un sistema específico de re-presentación: aquel en el cual la abstracción aparece encerrada en la figuración, lo cual aclararía o demostraría la existencia latente de un eespiritu abstractos en este arte y al mismo tiempo justificaría el esquematismo de su figuración.

d. En la re-presentación existen además elementos plásticos que se escapan de la sumisión al objeto. Son las líneas ornamentales que, en ocasiones, puede también reducirse a figuras geométricas simples y que también pueden poseer una significación simbólica. En el ejemplo de la Biblia de Roda, la línea ornamental poseía una imagen geométrica (el triángulo) y un simbolismo específico (disolución). Según la interpretación de la imagen y re-presentación del folio, en esta linea ornamental se encontraba condensado todo el significado pues en ella se expresaba la nueva idea del poder que tanto la re-presentación como la imagen desarrollaban según su propio lenguaje, iconográfico y rítmico, respectivamente.

El perfeccionamiento metodológico en el acceso a la obra de arte como documento, supondría la posibilidad de disponer de una nueva dimensión cognoscitiva de lo imaginario de las sociedades y, al mismo tiempo, un considerable enriquecimiento en la comprensión del arte a la luz de la historia social. 